• 研究报告・

\title{
印度野牛在中国的分布及其栖息地适宜性分析
}

\author{
丁晨晨 $1,2 \#$ 胡一鸣 $1,2 \#$ 李春旺 ${ }^{1,2}$ 蒋志刚 $1,2 *$ \\ 1 (中国科学院动物研究所动物生态与保护生物学重点实验室, 北京 100101) \\ 2 (中国科学院大学, 北京 100049)
}

\begin{abstract}
摘要: 印度野牛(Bos gaurus)在中国分布在云南省南部和西藏藏南地区。2016年2-3月和2016年11-12月, 我们在西 双版纳州、普洱市及高黎贡山区域开展印度野牛调查, 并对藏南地区进行文献调研, 共获得47处印度野牛有效出 现位点数据。目前云南地区印度野牛种群数量约180-210头, 面临着严重的生存危机; 在高黎贡山未发现印度野 牛。利用印度野牛分布位点数据, 选取地形、土地覆被类型、人类足迹指数、距水源和道路距离以及气候共 5 类 14 种因子作为自变量建立MaxEnt生态位模型, 通过模拟云南和西藏印度野牛的适宜分布区, 分析各环境因子对该物 种分布的影响。结果表明: 模型预测精度较高, 平均AUC (area under the curve)值为0.994。印度野牛潜在适宜栖息 地可划分为高适宜、次适宜、低适宜和不适宜 4 个等级。高适宜栖息地主要分布在云南省西双版纳和藏南地区, 其 中西双版纳部分镶嵌有次适宜和低适宜栖息地斑块, 面积为 $4,987 \mathrm{~km}^{2}$; 藏南部分高适宜栖息地面积为 $13,995 \mathrm{~km}^{2}$ 。 次适宜栖息地主要分布于云南省南部、高黎贡山区域以及藏南高适宜栖息地区的边缘, 总面积为 $32,778 \mathrm{~km}^{2}$ 。低适 宜和不适宜栖息地区连接成片, 位于云南省中部、北部地区和藏南地区北部。Jackknife检验结果显示, 季节温度 变化和等温线对印度野牛潜在分布区的影响较大, 而地形因子和降水变化的影响较弱。遥感地物分类结果表明: 橡胶林等人工经济林的种植占据了西双版纳野牛的适宜栖息地, 降低了景观连接度。建议管理部门加大对天然林 的保护力度, 控制橡胶林等人工林在野牛适宜栖息地的扩张, 提高景观连接度, 以促进该物种种群的恢复。
\end{abstract}

关键词: 云南; 藏南; 印度野牛; 生态位模型; 橡胶林; 栖息地适宜性

\section{Distribution and habitat suitability assessment of the gaur Bos gaurus in China}

Chenchen Ding ${ }^{1,2 \#}$, Yiming $\mathrm{Hu}^{1,2 \#}$, Chunwang $\mathrm{Li}^{1,2}$, Zhigang Jiang ${ }^{1,2 *}$

1 Key Laboratory of Animal Ecology and Conservation Biology, Institute of Zoology, Chinese Academy of Sciences, Beijing 100101

2 University of Chinese Academy of Sciences, Beijing 100049

\begin{abstract}
Gaur (Bos gaurus) are found in the Yunnan Province and Zangnan in southern Tibet in China. We conducted two field surveys in Xishuangbanna, Pu'er and Mt. Gaoligongshan in Yunnan Province, from February to March and November to December in 2016. We collected 47 valid occurrence locations of gaur by combining survey data and records from literature. Our analysis suggests that there are 180-210 gaurs in the Yunnan Province which face a serious survival crisis. No gaur signs were found in Mt. Gaoligongshan. Next, we used MaxEnt models to predict the potentially suitable habitats for gaur. We grouped 14 habitat predictor variables into five classes - terrain, land cover type, human footprint index, the distance to water and road, as well as climatic factors, and determined the contribution of each habitat factor to habitat suitability for gaur. The accuracy of our prediction models was accessed by the area under the curve (AUC) values for a receiver operating characteristic (ROC) curve. The validation showed that the results had high average AUC value of 0.994 . The simulated potential habitat was divided into four classes - the most suitable habitat, moderately suitable habitat, low suitability habitat, and unsuitable habitat. The most suitable habitats for gaur
\end{abstract}

收稿日期: 2018-01-11; 接受日期: 2018-05-26

基金项目: 国家重点研发计划项目(2016YFC0503304, 2016YFC0503303)、国家自然科学基金(31372175)和全国第二次陆生野生动物资源调查专项调查 资助。

\# 共同第一作者 Co-first authors

* 通讯作者 Author for correspondence. E-mail: jiangzg@ioz.ac.cn 
are mainly located in southern Yunnan and Zangnan and spanned 4,987 $\mathrm{km}^{2}$ and 13,995 km² respectively. Habitats with moderate suitability (total area $=32,778 \mathrm{~km}^{2}$ ) were located in the marginal areas of the most suitable habitats and in the Mt. Gongligongshan area. The most suitable habitats were mixed with habitat patches of moderate and low suitability for gaur in the southern parts of Xishuangbanna. In contrast, the central and northern parts of the study area were classified entirely as low suitable habitats and unsuitable habitats. The results of a Jackknife test indicated that temperature seasonality and isothermality had the strongest influence on habitat suitability for gaur, whereas terrain factor and precipitation had little effect. Temperature difference, land cover type and human footprint index were the main variables that explained patterns of gaur distribution. The results of land cover classification (using remote sensing) showed that rubber plantations have fragmented the suitable habitat and reduced landscape connectivity for gaur. We recommend that the relevant management authorities should protect natural forests, control the development of rubber plantations and other agricultural development in habitats suitable for gaur, and improve landscape connectivity to restore gaur populations in the landscape.

Key words: Yunnan; Zangnan; Bos gaurus, ecological niche model, rubber plantations, habitat suitability assessment

印度野牛(Bos gaurus)又称白肢野牛, 是牛科 中体型最大的一种, 成年个体肩高可达 $2 \mathrm{~m}$, 体重 可达900 kg。其两角粗大而尖锐, 体毛棕褐色或黑 色, 肩部有一个瘤状隆起, 因其四肢膝盖以下的毛 为白色, 故又名“白袜子”(杨德华和张家银, 1988)。 印度野牛主要分布于南亚次大陆至马来半岛的热 带地区，包括中国、印度、尼泊尔、不丹、孟加拉 国、缅甸、泰国、越南、老挝和马来西亚(Choudhury, 2002), 栖息于热带和亚热带阔叶林、沟谷雨林、竹 林或稀树草原, 偶尔也在林缘草地活动, 以草本植 物、树叶、嫩枝、树皮等为食(甘宏协和胡华斌, 2008), 栖息地海拔高度为600-1,900 m (张洪亮等, 2000)。 印度野牛是我国一级重点保护野生动物, 世界自然 保护联盟(IUCN)将其列为易危物种(Duckworth et al, 2016), 中国脊椎动物红色名录将其列为 “极危” 级 (蒋志刚等, 2016)。由于乱捕滥猎、野牛角贸易、栖 息地破碎化以及源自家养动物的传染性疾病, 种群 数量日益减少。

在过去的一个世纪, 全球印度野牛数量减少了 $80 \%$, 并且还在持续下降(Choudhury, 2002)。目前印 度野牛在各主要分布区形成孤立种群, 估计数量共 15,000-35,000头, 成熟个体仅有 6,000-21,000头 (Duckworth et al, 2016)。在我国，印度野牛曾分布于 云南省的西双版纳、普洱和高黎贡山区域(寿振黄和 蔡希陶, 1958), 以及西藏藏南地区 (潘清华等, 2007)。我国对云南省的印度野牛种群共进行过4次 调查, 分别发现印度野牛 500 头(杨德华和张家银, 1988)、532头(云南省林业调查规划院，1989)、400
头(国家林业局, 2009; 尹峰等, 2015)、152-167头(张 忠员等, 2016)。我国藏南地区的印度野牛与印度东 北部以及尼泊尔、不丹的印度野牛形成一个连续的 种群，估计共有 5,000-8,000头(Choudhury, 2002)。

受人口增长和经济利益驱动, 印度野牛历史分 布区的土地利用类型发生改变。例如, 20世纪90年 代以来, 西双版纳以橡胶林为主导的经济种植园发 展迅速, 造成橡胶林与热带雨林矛盾日趋突出, 给 当地脆弱的生态环境造成了很大的压力(刘晓娜等, 2012)。在藏南, 印度野牛也面临着栖息地丧失的困 境, 1979-1995年藏南地区印度野牛栖息地面积净 损失 $20,800 \mathrm{~km}^{2}$, 种群数量也呈下降的趋势(Choudhury, 2002)。

栖息地为野生动物提供了生存、繁衍所必需的 资源(Hall et al, 1997), 是影响野生动物生存和发展 的重要因素, 对濒危物种进行栖息地评价和预测是 有效保护的基础(Costanza et al, 1997; Margules \& Pressey, 2000)。因此, 我们结合野外考察和文献调 研, 应用GIS技术和MaxEnt模型模拟分析, 研究印 度野牛在中国的分布现状、潜在适宜分布区以及西 双版纳人工林对印度野牛栖息地连接度的影响; 探 讨影响印度野牛空间分布的主要环境因子, 了解西 双版纳地区栖息地破碎化状况, 以期为该物种的管 护并促进种群发展提供科学依据。

\section{研究地概况}

云南省面积约 39 万 $\mathrm{km}^{2}$, 地势北高南低, 海拔 在76-6,740 m之间, 年温差为 $10-15^{\circ} \mathrm{C}$, 全省大部分 
地区年降水量 $1,100 \mathrm{~mm}$ 左右, 兼具低纬气候、季风 气候、山原气候的特点。云南省属古北界动物和东 洋界动物的交汇地带, 是世界十大生物多样性热点 地区之一东喜马拉雅地区的核心区域, 有包括滇金 丝猴 (Rhinopithecus bieti)、白颊长臂猿(Nomascus leucogenys)、天行长臂猿(Hoolock tianxing)、小熊猫 (Ailurus fulgens)、威氏小鼠鹿(Tragulus williamsoni)、 印度野牛、亚洲象(Elephas maximus)、绿孔雀(Pavo muticus)、双角犀鸟(Buceros bicornis)等动物在内的 60 种国家一级保护动物和182种国家二级保护动物。

西双版纳傣族自治州位于云南省南部边缘, 是 我国生物多样性荟萃地(张洪亮等, 2000)。怒江州地 处青藏高原南延的横断山脉中段, 地质构造复杂, 山高谷深, 海拔 $4,000 \mathrm{~m}$ 以上的山峰多达 40 余座。其 中高黎贡山动植物资源丰富, 素有 “世界动植物基 因库之称”, 也是印度野牛的历史分布区，但近些 年已没有印度野牛活动踪迹的报道(朱振华等, 2003; Duckworth et al, 2016)。

藏南地区位于喜马拉雅山脉南侧, 包括了西藏 自治区错那、隆子、墨脱和察隅四县的大部分及郎 县、米林两县的部分国土。藏南地区属于亚热带、 热带季风气候, 海拔落差大, 水热条件优越, 年平 均降水在9,000 mm左右, 是世界上降水量最大的地 区之一; 森林覆盖率达 $90 \%$ 以上。藏南地区所属的 东喜马拉雅区域是全球生物多样性热点地区之一 (Myers et al, 2000), 也是印度野牛在中国的历史分 布区之一。Mishra等(2006)报道了藏南地区35种哺 乳动物, 其中有戴帽叶猴(Trachypithecus pileatus)、 喜马拉雅斑羚(Nemorhaedus caudatus)、喜马拉雅黑 熊(Ursus thibetanus)、雪豹(Panthera uncia)、云豹 (Neofelis nebulosa) 等珍稀濒危物种。由于国土边界 争议问题, 过去我们对藏南地区的哺乳动物知之甚 少, 《中国哺乳动物多样性》(第2版)收录了藏南地 区16种哺乳动物(蒋志刚等, 2017), 明确了我国藏南 地区哺乳动物分布记录。

\section{研究方法}

\section{1 野外调查方法}

本次野外调查于 2016年2月22日至3月 8日, 11 月19日至12月5日进行。印度野牛数量少, 且活动范 围大, 较难在野外发现实体, 所以在种群数量调查 中以社区访问为主。通过访问保护区或保护站工作
人员、护林员、森林公安、边防官兵、农牧民及其 他熟悉当地环境和动物情况的人员，询问当地野牛 及其他野生动物的活动状况、数量、发现地点及时 间，获取关于野牛的信息。在社区访问中，先让被 访者描述物种的形态，然后以印度野牛照片和《中 国兽类野外手册》(Smith和解炎, 2009)作为辅助的 辨识工具, 让被访者确认其所描述物种的图片。判 断可信原则: 第一, 被访人能够正确指出印度野牛 照片者，则继续进行访问，否则被访人提供的信息 无效; 第二，在指出正确照片的基础上，被访人能 够描述印度野牛的形态与习性，该受访者的描述信 息可信度较高; 第三，被访问人提供遇见印度野牛 的时间和地点, 则认为可信度最高。本次访问调查 了 22 个村寨, 综合西双版纳自然保护区积累的资料, 获取了印度野牛分布信息以及影像资料(附录1)。

在西双版纳地区、普洱市思茅区和怒江州高黎 贡山-独龙江流域，根据区内自然状况、野牛种群历 史分布状况布设样线, 每条样线长度在2-6 km之间, 样线总长为 $38.4 \mathrm{~km}$ 。样线涉及区域如下: (1)景洪市 基诺山区域：基诺山寨-龙迫村；(2)普洱市思茅区 域: 弯手寨-大车树村、茨竹林-芒坝村、芒坝村大金山; (3)预海县贺建乡区域: 纳板河自然保护区过门Y口; (4)纳板河区域: 过门山-糯有上寨; (5)预 海县预满区域: 帕迫村-四谷坪、朝山寨-羊屋; (6) 澜沧县发展河区域：预乃村-发展河村; (7)怒江傈 傈族自治州区域: 高黎贡山-独龙江流域。样线覆盖 海拔范围为688-1,928 m的沟谷和山脊，并以保护 区工作人员、护林员为向导, 记录动物实体及足迹 (链)、食痕、毛发、粪便、卧迹等活动痕迹, 用GPS 记录发现点的地理坐标信息。

\section{2 种群数量的估算}

在野外调查的基础上, 云南地区印度野牛种群 数量通过直接计数法得出, 即直接累加得到该分布 区同时期的种群大小; 如果没有观察到实体，但有 较多粪便和活动痕迹，访问周边牧民和护林员得到 种群数量。由于社区访问得到的数据往往不是精确 的数字, 将从各个调查点通过样线法和访问法得到 的野牛数量区间的最小值与最大值分别累加得出 我国云南地区野牛总数量的区间。

\section{3 潜在适宜栖息地分析}

\subsection{1 印度野牛分布点数据}

通过2016年2-3月和2016年11-12月分别对云 
南西双版纳、普洱思茅区和高黎贡山开展2次野外 调查, 并结合前人在2002-2015年的研究, 共收集 了 47 处印度野牛出现点数据(图1), 其中包括藏南地 区11处(Choudhury, 2002)。

\subsection{2 环境变量数据}

从世界气象数据库(http://www.worldclim.org/) 中下载全球 19 个生物气候因子的 $1 \mathrm{~km}^{2}$ 分辨率的栅 格文件(1950-2000年), 用ArcGIS 10.2提取气候变 量作为模型预测的栖息地变量, 然后经过主成分分 析和相关分析，去除气候变量中相关性较大的因子， 从而获取独立变量(表1)。其中距主要道路和水源地 的距离数据来源于国家测绘地理信息局网站 $1: 10$ 万 矢量地图 (http://www.sbsm.gov.cn/), 通过 ArcGIS 10.2 空间分析工具提取欧几里得距离获得; 海拔和 坡度采用中国科学院科学数据库分辨率 $30 \mathrm{~m} \times 30$ $\mathrm{m}$ 的数字高程(DEM)数据, 在ArcGIS 10.2中进行空 间分析获得。植被覆盖数据从全球土地覆盖利用数 据库(http://www.landcover.org/)获取, 共分为16种土 (http://sedac.ciesin.columbia.edudata/collection/wildar eas-v1)。

\subsubsection{MaxEnt模型构建}

以ArcGIS 10.2为平台, 分别建立各环境变量的 栅格文件，并且按照MaxEnt 3.3.3k (Phillips et al, 2006)软件要求将所有图层统一边界和坐标系统。采 用 $30 \%$ 的分布点作检验，重复数设为 10 , 重复运行 类别选择交叉验证 (cross-validate), 使用刀切法 (Jackknife test)评价各环境因子对印度野牛分布的 贡献，其他参数默认设置。在模型预测分布图中“0” 表示最不适宜栖息地, “1”表示最适宜栖息地。根据 模型标准及图层栅格出现概率重分类，选取栖息地 适宜性指数 $0-0.2$ 为不适宜、0.2-0.5为低适宜、0.5-0.7 为次适宜, 0.7-1.0为高适宜栖息地。

\subsection{4 模型检验方法}

ROC曲线指受试者工作特征曲线(receiver operating characteristic curve), 是反映模型敏感性和特 异性连续变量的综合指标，它通过将连续变量设定 出多个不同的临界值，从而计算出一系列敏感性 (sensibility)和特异性，再以敏感性为纵坐标、1-特

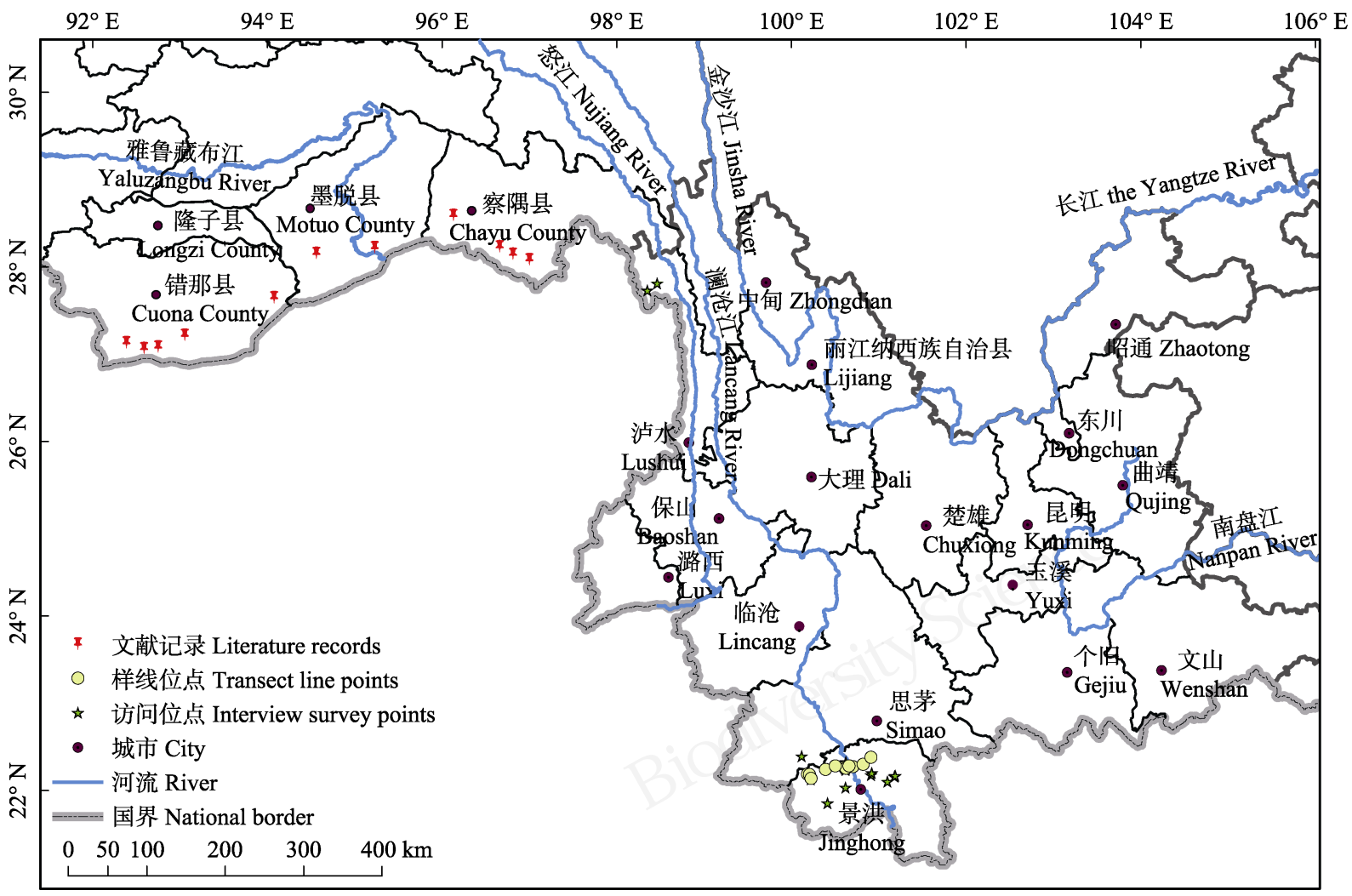

图1 中国印度野牛出现点分布图

Fig. 1 Occurrence points of gaur in China 
表1 模拟印度野牛适宜分布区时所用的环境变量

Table 1 Environmental variables used to model the potential distribution range of the gaur

\begin{tabular}{lll}
\hline 编码 Code & 描述 Description & 来源 Source \\
\hline BIO1 & 年均温 Annual mean temperature & WorldClim database Version 1.4 \\
BIO3 & 等温线 Isothermality & WorldClim database Version 1.4 \\
BIO4 & 季节温度变化 Temperature seasonality & WorldClim database Version 1.4 \\
BIO7 & 气温年较差 Temperature annual range & WorldClim database Version 1.4 \\
BIO9 & 最早季均温 Mean temperature of driest quarter & WorldClim database Version 1.4 \\
BIO12 & 年均降水量 Annual precipitation & WorldClim database Version 1.4 \\
BIO15 & 降水季节性 Precipitation seasonality & WorldClim database Version 1.4 \\
BIO19 & 最冷季均温 Precipitation of coldest quarter & WorldClim database Version 1.4 \\
LCT & 土地覆被类型 Land cover type & Global Land Cover Facility \\
HFI & 人类足迹指数 Human footprint influence & Last of the Wild Data Version 2 \\
ALT & 海拔 Altitude & Chinese Natural Resources Database \\
Slop & 坡度 Slope & Chinese Natural Resources Database \\
Dis_road & 距主要道路距离 Distance to major roads & National Catalogue Service for Geographic Information \\
Dis_water & 距水源地距离 Distance to water source & National Catalogue Service for Geographic Information \\
\hline
\end{tabular}

异性(1-specificity)为横坐标绘制成曲线, ROC曲线 下的面积即为AUC值(Leshowitz，1969; 王运生等, 2007)。AUC越大, 表示物种分布越偏离随机分布, 环境变量与模型的相关性越大, 诊断准确性越高, 模型预测结果越可信(Catry et al, 2009)。评定标准设 为: AUC 值为 0.5-0.6, 不及格; $0.6-0.7$, 较差; 0.7-0.8, 一般; 0.8-0.9, 良好; 0.9-1.0, 优秀(Swets, 1988; Araujo et al, 2005)。

\section{4 土地覆被类型遥感分类和空间分析}

从地理空间数据云网站获取西双版纳地区 Landsat 8 OLI 2016年2-3月的遥感影像, 使用ENVI 5.1 对影像进行非监督分类。选用IsoData方法(迭代 自组织数据分析技术)计算数据空间中均匀分布的 类均值, 然后用最小距离技术将剩余像元迭代聚集 (Ball \& Hall, 1967)。执行非监督分类之后, 获得了 一个初步的分类结果, 接着进行类别定义和合并子 类的操作, 并结合Google-Earth高分辨率卫星影像 进行目视解译、地物分类, 然后进行分类后处理统 计操作，最后结合模型栖息地模拟结果进行分析。

\section{3 结果}

\section{1 印度野牛种群数量与分布现状}

印度野牛分布在云南南部和藏南, 而怒江傈僳 族自治州高黎贡山区的印度野牛已经灭绝, 仅有人 工养殖的独龙牛群体。云南纳板河流域国家级自然 保护区内设置的3条样线, 共记录到28处野牛活动
痕迹，结合社区访问结果，估计当地有3-4群42-62 头印度野牛分布; 在普洱市思茅区茨竹林和发展河 村分别发现有23-24、7-10头印度野牛; 藏南地区因 缺乏调查, 种群数量未明。本研究综合样线调查、 社区访问和纳板河流域国家级自然保护区的资料, 估计我国云南地区共有180-210头印度野牛，分布 在西双版纳州跁海县的秒宋乡朝山寨、跁满镇的糯 有上寨、糯有下寨、纳包村(金矿山)、老田寨后山, 预腊的象明乡安乐村, 景洪的基诺乡扎吕村、大渡 岗乡、纳板河过门山以及普洱市思茅区茨竹林、 发展河等地。

\section{2 印度野牛栖息地适宜度分析}

\subsection{1 模型预测效果检验}

ROC 曲线评价结果为: 验证集的 AUC 值为 0.994 (附录2), 表明MaxEnt模型的预测结果较好, 所建模型可以用于分析云南地区和藏南地区印度 野牛的分布情况。

\subsection{2 栖息地变量篮选结果}

从19个气候变量中选取 8 个独立变量和其他 6 个变量作为最终模型环境参数。由刀切法(图2)测定 栖息地变量的重要性中可以看出, 地形因子(海拔、 坡度)及距道路(Dis_road)和距水源(Dis_water)的距 离对其分布影响较小, 环境变量中对预测结果贡献 较大的因子(测试得分 > 1.5)分别是季节温度变化 (BIO4)、等温线(BIO3)、最冷月均温(BIO7)、人类 足迹指数 $(\mathrm{HFI})$ 。 


\subsection{3 各种栖息地变量对MaxEnt模型预测的影响}

反馈曲线(附录3)显示了每个栖息地变量对模 型预测结果的影响。海拔、坡度、距离道路和水源 的距离及年均温(BIO1)、年均降水量(BIO12)、降水 季节性(BIO15)的变化对MaxEnt模型预测的结果不 明显，等温线(BIO3)、季节温度变化(BIO4)、气温 年较差 $(\mathrm{BIO})$ 、人类足迹指数 $(\mathrm{HFI})$ 及土地覆被类型 (LCT)的变化对MaxEnt模型预测结果的影响较明显, 而其他变量的变化没有较大的影响。

\subsection{4 印度野牛栖息地适宜性分布}

由生物气候因子影响预测, 印度野牛在我国的 适宜分布区为云南省和西藏藏南地区(图3)。云南省 南部西双版纳秒海县及预腊南部地区栖息地适宜性 指数在 $0.7-1.0$ 之间, 为高适宜栖息地, 其中夹杂着 次适宜和低适宜斑块, 总面积为 $4,987 \mathrm{~km}^{2}$, 所占面 积比例仅为云南省的 $1.4 \%$; 次适宜栖息地分为两部 分, 一部分位于西双版纳州高适宜栖息地周边, 一 部分位于高黎贡山区域，总面积为 $16,633 \mathrm{~km}^{2}$, 所 占面积比例为 $3.9 \%$; 低适宜栖息地主要集中在云南 省中南部地区, 所占比例较大, 呈连续分布, 包括 临沧、潞西、保山和泸水辖区, 栖息地适宜性指数 为 $0.2-0.5$ 之间, 总面积为 $76,015 \mathrm{~km}^{2}$; 云南中部和 北部其他地区模型预测结果为不适宜栖息地，总面
积为 $287,256 \mathrm{~km}^{2}$, 所占面积比例为 $74.9 \%$ 。藏南地区 高适宜栖息地主要集中在南部, 面积为 $13,995 \mathrm{~km}^{2}$, 次适宜栖息地主要集中在藏南中南部，面积为 $16,145 \mathrm{~km}^{2}$ 。综上，西藏藏南地区和西双版纳是印度 野牛在我国的主要分布区，仍保留着较大面积的潜 在适宜栖息地。

\section{3 西双版纳和藏南地区土地覆被空间分布}

西双版纳2016年土地覆被非监督分类结果共 分为4类，分别为林地或草地、橡胶林或茶园、耕地 或建设用地和其他(图4)。西双版纳地区是以林地为 主导的土地覆被类型和以橡胶林地为主导的土地 利用类型, 橡胶林地和茶园表现出较为明显的集中 分布特征，主要分布在景洪市和虸腊县，预海县在 西南边境和西侧以及北侧靠近景洪市的地区有橡 胶林，占西双版纳全境面积的 $38.66 \%$; 而林地所占 面积只有 $37.57 \%$, 主要分布在景洪市和预腊县, 而 草地类型较为分散且总体面积较小，主要分布在林 地周边，总体上呈小斑块分布。西双版纳区域内潜 在适宜分布区和橡胶林或茶园土地利用类型叠置 分析结果表明，西双版纳境内印度野牛潜在适宜分 布区面积为 $12,386 \mathrm{~km}^{2}$, 其中适宜栖息地(适宜度大 于 0.5$)$ 中橡胶林和茶园占 $30.42 \%$, 林地和草地类型 占 $48.63 \%$ 。随着橡胶林种植面积的扩张，受食物资

对印度野牛刀切法训练收获

Jackknife of regularized training gain for Bos gaurus

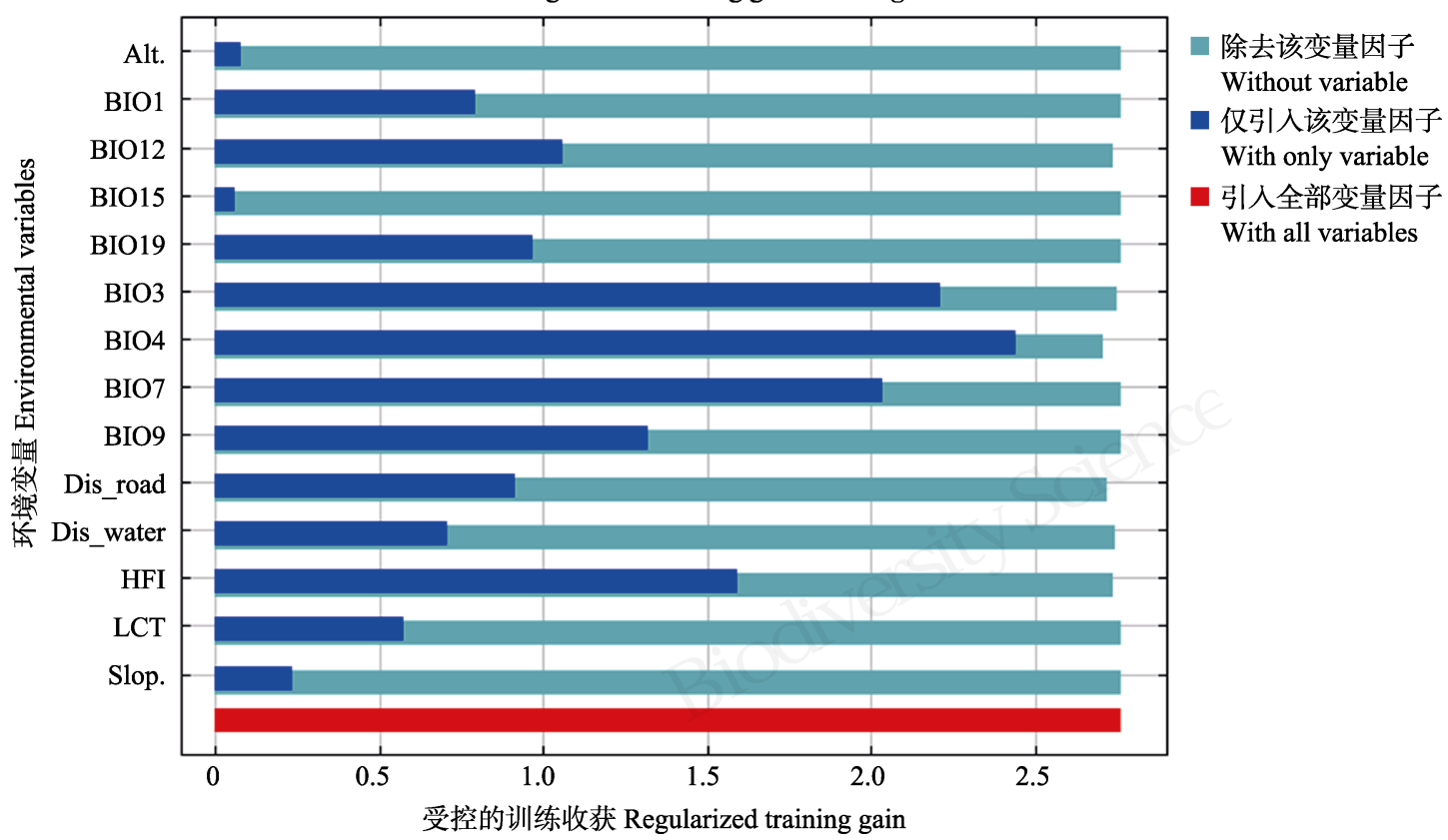

图2 环境因子对印度野牛分布作用的Jackknife刀切法评价

Fig.2 Jackknife evaluation of environmental variables in gaur distribution 


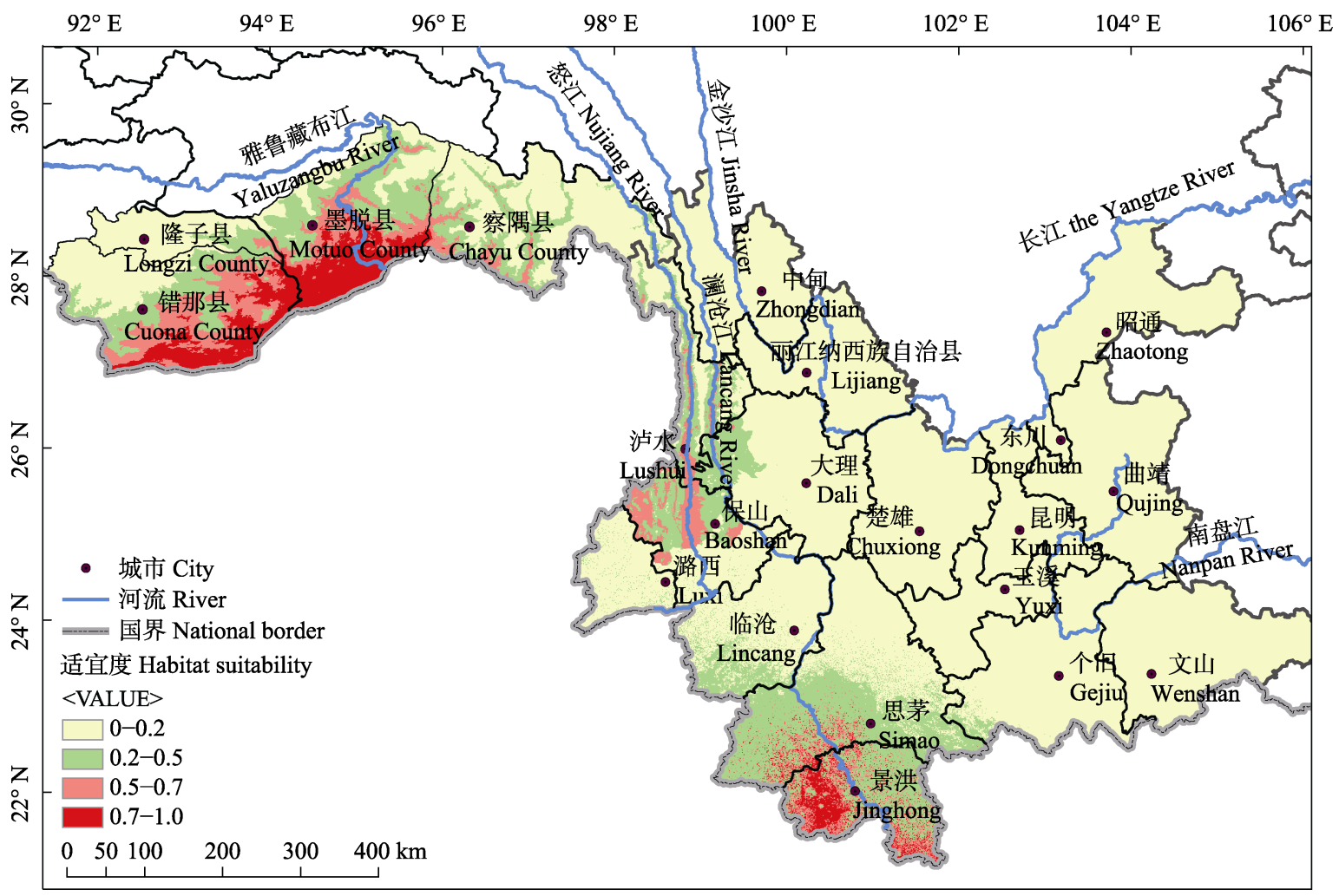

图3 中国印度野牛潜在适宜栖息地分布图

Fig. 3 Potential suitable habitats of gaur in China

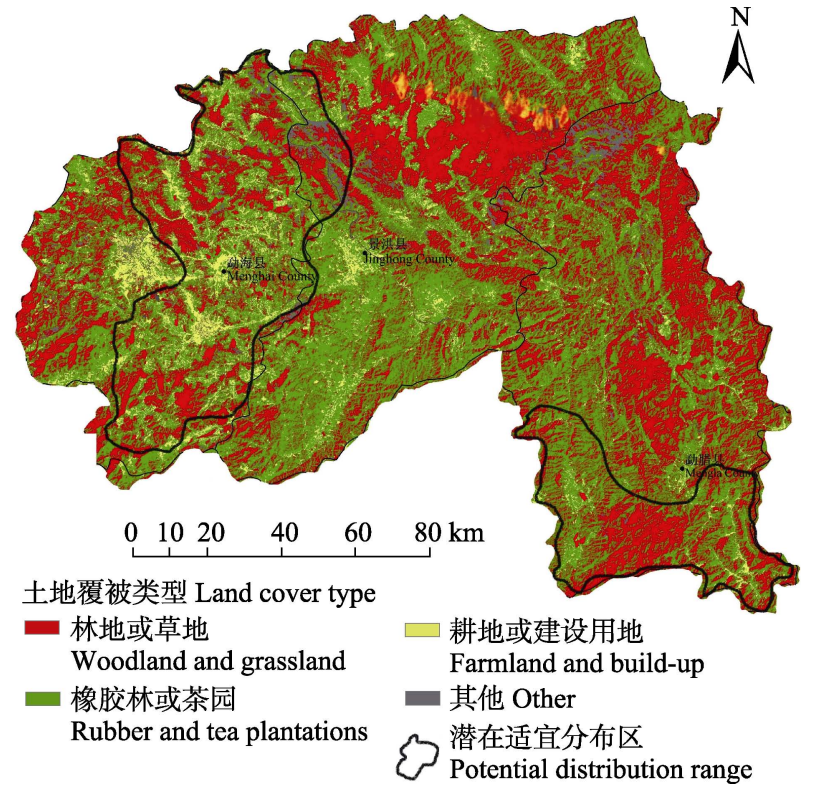

图4 2016年西双版纳土地覆被类型

Fig. 4 Land use in Xishuangbanna in 2016

源及人为干扰影响, 印度野牛适宜栖息地面积随之 减少且形成隔离斑块。

藏南地区生境原始，根据我们的土地覆被类型 分析方法, 该区林地类型的生境面积(林地、灌木林
与疏林地)比例高达 $80.21 \%$, 草地面积比例为 $9.01 \%$, 裸岩与冰川面积为 $9.78 \%$, 人工用地仅为 $1.02 \%$ 。该 区以林地和草地为主, 林地呈全区密集分布特征, 草地主要集中在藏南南部低海拔区域; 人类足迹指 数平均为 11.6 , 人为干扰较少。藏南地区潜在适宜 分布区与土地覆被类型的叠置结果表明, 潜在适宜 栖息地里林地和草地类型占 $91.26 \%$ 。

\section{4 讨论}

\section{1 印度野牛在中国的种群数量分布}

印度野牛为典型的热带物种, 在我国属于边缘 分布。此次印度野牛分布及数量状况调查范围包含 西双版纳、普洱部分地区以及怒江傈傈族自治州部 分地区，发现印度野牛的分布区范围持续减小，高 黎贡山区的印度野牛已经灭绝, 但仍是印度野牛的 潜在分布区。藏南地区仍保留着大面积的印度野牛 适宜栖息地, 人为活动较少, 仍可支持可持续种 群。由于近年来土地利用类型转变和栖息地退化, 藏南地区印度野牛的分布范围也在逐步退缩, 种群 数量也在下降(Choudhury, 2002; Duckworth et al, 2016)。西双版纳州印度野牛种群数量从1958年的近 
千头(寿振黄和蔡希陶，1958)至1988年的605-712头 (杨德华和张家银, 1988), 再到现有数量180-210头, 这与偷猎以及 20 世纪 90 年代以来橡胶林的大面积 种植造成野牛适宜栖息地面积较少和破碎化等因 素有关。在西双版纳州㖵宋朝山寨, 预满纳包村、 老田寨后山, 思茅茨竹林, 发展河林排坡、预乃村, 保留有较大面积连续分布的天然林和草地, 至今仍 能看到野牛实体; 其中在思茅区茨竹林发现有 23-24头野牛。1996年景洪市大渡岗地区曾发现 32-33头野牛, 可能是由于迁移的原因, 近些年已 未再发现。2006年, 纳板河流域国家级自然保护区 发现有野牛30-75头, 我们利用活动痕迹估计, 当 地仍有3-4群42-62头野牛, 说明保护区内生态状况 良好, 是印度野牛目前分布较为稳定和集中的区 域。总体而言, 野牛种群分布范围和数量呈缩小趋 势, 在野牛历史分布区的不少地方近些年已经没有 野牛活动迹象，保护野牛已迫在眉眏。

\section{2 预测模型评估}

非生物的因素(主要是气候因素)主要在大尺度 空间影响物种的分布, 这些因素很大程度上决定了 物种的分布范围和格局, 包括生理制约、物种对气 候和栖息地梯度的响应和选择等(Pearson \& Dawson, 2003)。张洪亮和王人潮(1999)运用Logistic回归 模型分析认为, 居民点以及植被类型对印度野牛的 影响在统计学上是显著的; 而李明阳等(2009)采用 GARP等生态位模型对印度大陆部分潜在适宜栖息 地结果对比显示, 中国藏南为潜在的印度野牛栖息 地。年平均降水量、温度季节性变化、林木覆盖率、 标准归一化植被指数、海拔高度、距主要道路距离 是影响印度野牛空间分布的主要环境因子。本次研 究运用现有印度野牛位点数据并增加人类足迹指 数变量, 模拟了印度野牛在中国藏南和云南的潜在 分布, 结果显示季节温度变化、等温线、气温年较 差对印度野牛适宜分布区的影响最大。这是由于印 度野牛是东南亚热带、亚热带动物区系物种, 对于 温度变化较为敏感。气候因子中季节温度变化在 200-350之间, 等温线变化在50-55之间, 气温年较 差在 $15-25^{\circ} \mathrm{C}$, 最旱季均温在 $13-20^{\circ} \mathrm{C}$, 是影响印度 野牛空间分布及适宜栖息地的选择特征; 人类足迹 指数整合了人口居住地、土地利用类型、道路网络、 基础设施建设等基本图层, 对印度野牛的适宜栖息 地有较大影响, 适宜干扰指数在0-15之间, 表明人
类活动较频繁的区域会影响印度野牛的分布，目前 西双版纳人类足迹指数平均值为 21.9 , 因此会对野 牛栖息地产生不利影响, 而藏南地区人类足迹指数 平均值为 11.6 , 说明人类干扰程度较小; 印度野牛 适宜分布区海拔为600-1,700 $\mathrm{m}$, 海拔和坡度等对 结果的贡献值不大, 可能是因为位点数据本身对海 拔和坡度没有呈现出明显的偏向性。因此增加林木 覆盖率、减少道路修建等人为活动引起的栖息地破 碎化应当成为保护印度野牛的措施。

从大尺度上分析野牛栖息地利用与栖息地因 子之间的关系，将野牛的栖息地需求与栖息地分布 综合一起分析, 这是生态位模型最大的特点(Hirzel et al, 2001)。本次调查运用MaxEnt模型方法, 采用 14 个环境变量数据结合刀切法, 结果表明印度野牛 潜在适宜栖息地已覆盖现生分布区，高适宜栖息地 主要集中在藏南、西双版纳预海县和预腊南部, 成 碎裂的小斑块分布，而高黎贡山历史分布区模型预 测为次适宜和低适宜栖息地，这与野牛实际分布区 相符。预测的潜在适宜分布区大于印度野牛实际的 占有面积, 原因是印度野牛的分布还受到人为干 扰、受食地(如草地)的面积、种内竞争(领域行为) 和空间阻隔等因素的制约。在西双版纳、普洱(包括 自然保护区在内), 由于自然迁徙路线的阻断，人为 经济活动的干扰，野牛适宜栖息地实际呈“孤岛”状 分布。甘宏协和胡华斌(2008)发现在纳板河和西双 版纳曼稿之间的野牛种群被预海县预海镇、预宋乡 和预阿乡所分隔, 需建立栖息地廊道, 以连通相隔 保护区。以保护野牛及解决人牛冲突为目的, 许多 研究者尝试利用GIS和空间建模的方法, 分析野牛 栖息地建立保护廊道的可行性。然而, 尹峰等(2015) 认为, 在缺乏基础生态学资料的情况下, 廊道地点 选择和建设缺乏依据, 难以科学评估其实施效果。 因此只有对模型理论有了深入的理解, 才能够促进 生态位模型在生物多样性保护领域得到运用。

\section{3 橡胶林等人工林对印度野牛适宜栖息地的影响}

景观连接度的高低能促进或阻碍生物体以及 生态过程在原斑块间运动的程度，反映了景观的功 能特征(陈利顶和傅伯杰, 1996)。城市区域的扩展和 集约化农业的土地利用，使野生物种栖息地不断萎 缩、隔离, 自然生境的消失和破碎化已成为全球生 物多样性的最大威胁。Heinen和Sompoad (1996)研 究显示栖息地丧失和破碎化是威胁野牛生存的最 
主要因素。由于林木采伐、土地开发、道路修建、 农作物种植等人为活动的干扰, 野牛的适宜栖息地 已丧失或严重破碎化。帕迫村辖区内的几万亩山林 被承包商承包种植思茅松(Pinus kesiya)、茶叶、杉 树等经济作物, 种植杉松(Abies holophylla)等经济 树种(张忠员等, 2016)。目前适合野牛生存的栖息地 已经为数不多。由于森林不断遭到破坏, 印度野牛 的迁徙路线被阻隔, 野牛成群集中出现在局部地带, 对农作物、果木甚至公民人身安全造成威胁和危害 (甘宏协和胡华斌, 2008)。Choudhury (2002)研究表 明, 藏南地区同样由于土地利用类型的转变, 印度 野牛栖息地也在不断退缩和破碎化。森林开垦导致 野牛食物及栖息地资源减少，因此野牛会选择栖息 地保存完好、受人为干扰少的区域活动。

森林的变化影响着生态系统服务功能, 包括生 物多样性维持、气候调节、碳储存和水供给(Foley et al, 2005)。据全球森林观察网站 (http://www.globalforestwatch.org/)数据, 云南2001-2015年以来森 林(树木覆盖度 > 20\%)面积减少了452,781 ha, 而 西藏减少了22,824 ha。另据中国自然观察报告2016 (http://chinanaturewatch.org), 云南西双版纳保护区 内发生的森林减少主要发生在该保护区实验区内。 因历史原因, 保护区对该实验区无管理权限。该保 护区实验区内的集体林转换为橡胶林和香蕉林, 使 得2000-2014年间保护区内森林总面积减少37\%。由 于橡胶、茶叶的大面积推广, 印度野牛的栖息地发 生了巨大改变, 片断化、孤岛化使区域内的印度野 牛种群分离成小种群(Conry, 1989)。橡胶林的大面 积种植会造成物种适宜栖息地的降级、隔离和生物 多样性的丧失(Li et al, 2007)。廖谌婳等(2014)利用 遥感方法研究也发现，1990-2014年西双版纳橡胶 林种植面积呈增加趋势, 橡胶林扩张以侵占天然林 为代价, 热带季雨林是受橡胶林扩张干扰最强烈的 天然林。这种景观类型转变会造成栖息地破碎化, 迫使动物离开原有栖息地, 对物种迁移形成障碍 (Sreekar et al, 2016), 进而造成野牛种群数量的下 降。据1990-1993年1：50万土地详查和遥感资料, 包括橡胶林和其他人工林在内, 森林覆盖率虽然达 到了 $64.2 \%$, 但约有 $50 \%$ 是人工林, 而人工林的边缘 效应和隔离效应会对生物多样性和动物物种栖息 地造成负面影响(廉振民和于广志, 2000)。对比此次 研究结果, 橡胶林地、茶园和林地占有超过 $75 \%$ 的
面积，其中橡胶林和茶园占有面积为 $41 \%$ ，而潜在 适宜分布区内橡胶林和茶园面积则占 $30.42 \%$, 林地 和草地被大面积成片橡胶林隔开形成片状斑块，橡 胶林等经济林树种单一, 林下植被稀疏, 且人为活 动频繁，占据并割裂了野牛的适宜分布区。对印度 野牛的栖息地利用和迁移产生不利影响。

\section{保育建议}

中国是印度野牛的边缘分布区，云南省南部是 我国印度野牛的主要分布区之一, 由于自然栖息地 的破坏和人为活动干扰的影响, 野牛种群面临着灭 绝的危险。建议: (1)西双版纳州野牛分布区高适宜 栖息地面积较小，橡胶林地侵占了野牛原有适宜分 布区，应加强天然林和草场的保护，在野牛分布区 域控制橡胶林等经济林的扩展，提升野牛适宜栖息 地连接度, 减小局域种群的灭绝风险。(2)印度野牛 分布区狭窄且适宜栖息地破碎化严重，西双版纳猛 腊县南部与老挝接壤区域，为野牛的潜在适宜分布 区，但还没有发现野牛实体。应加强野牛现有适宜 栖息地保护, 严格评估农田开垦以及道路建设活动, 在充分掌握野牛生态习性的基础上，规划建立生态 廊道，尝试联合老挝、缅甸建立跨国自然保护区， 促进其种群间基因交流和种群数量恢复。(3)印度野 牛种群数量很少并呈下降趋势, 藏南地区种群数量 未明, 应进一步开展印度野牛种群动态监测, 并开 展野牛种群遗传结构研究, 为制定和实施保护措施 提供依据。(4)现有自然保护区并不能庇护所有野牛 种群，保护区外、村寨周边也有野牛分布。为了有 效地保护印度野牛, 林业局、保护区管理局、以及 村委会之间应建立起保护网络，尝试在保护区周边 为印度野牛建立保护小区，加强保护宣传，鼓励村 寨民众参与，从而对区域内野牛种群进行有效保护。

致谢: 感谢广东省生物资源与应用研究所的胡慧建 研究员、周智金博士、蓝道英博士、黄志文、覃海 华等在野外调查与数据分析中给予的帮助和建议; 感谢崔绍朋博士在模型方法上提供的帮助; 感谢云 南省林业厅、云南西双版纳国家级自然保护区、云 南纳板河流域国家级自然保护区和云南高黎贡山 国家级自然保护区对野外工作的大力支持; 最后感 谢参与野外科考的所有工作人员。 


\section{参考文献}

Araujo M, Pearson R, Thuiller WM (2005) Validation of species-climate impact models under climate change. Global Change Biology, 11, 1504-1513.

Ball GH, Hall DJ (1967) A clustering technique for summarizing multivariate data. Behavioral Science, 12, 153-155.

Catry FX, Rego FC, Bação F, Moreira F (2009) Modeling and mapping wildfire ignition risk in Portugal. International Journal of Wildland Fire, 18, 921-931.

Chen LD, Fu BJ (1996) The ecological significance and application of landscape connectivity. Chinese Journal of Ecology, 15, 37-42. (in Chinese with English abstract) [陈利顶, 傅伯杰 (1996) 景观连接度的生态学意义及其应用. 生 态学杂志, 15, 37-42.]

China's State Forestry Administration (2009) National Survey on Key Terrestrial Wildlife Resources in China. China Forestry Publishing House, Beijing. [国家林业局 (2009) 中国 重点陆生野生动物资源调查. 中国林业出版社, 北京.]

Choudhury A (2002) Distribution and conservation of the gaur Bos gaurus, in the Indian subcontinent. Mammal Review, 32, 199-226.

Conry PJ (1989) Gaur Bos gaurus, and development in Malaysia. Biological Conservation, 49, 47-65.

Costanza R, D’Arge R, Groot RD, Farber S, Grasso M, Hannon B, Limburg K, Naeem S, Neill R, Paruelo J, Raskin RG, Sutton P, Belt M (1997) The value of the world's ecosystem services and natural capital. World Environment, 25, 3-15.

Duckworth JW, Sankar K, Williams AC, Samba KN, Timmins RJ (2016) Bos gaurus. The IUCN Red List of Threatened Species. http://www.iucnredlist.org/details/2891/0. (accessed on 2017-12-21)

Foley JA, Defries R, Asner GP, Barford C, Bonan G, Carpenter SR, Chapin FS, Coe MT, Daily GC, Gibbs HK, Helkowski JH, Holloway T, Howard EA, Kucharik CJ, Monfreda C, Patz JA, Prentice C, Ramankutty N, Snyder PK (2005) Global consequences of land use. Science, 309, 570-574.

Gan HX, Hu HB (2008) Biodiversity conservation corridor design based on habitat selection of gaur (Bos gaurus): A case study from Xishuangbanna, China. Chinese Journal of Ecology, 27, 2153-2158. (in Chinese with English abstract) [甘宏协, 胡华斌 (2008) 基于野牛生境选择的生物多样 性保护廊道设计: 来自西双版纳的案例. 生态学杂志, 27 , 2153-2158.]

Hall LS, Krausman PR, Morrison ML (1997) The habitat concept and a plea for standard terminology. Wildlife Society Bulletin, 25, 173-182.

Heinen JT, Sompoad S (1996) Status and protection of Asian wild cattle and buffalo. Conservation Biology, 10, 931-934.

Hirzel AH, Helfer V, Metral F (2001) Assessing habitat-suitability models with a virtual species. Ecological Modelling, 145, 111-121.

Jiang ZG, Jiang JP, Wang YZ, Zhang E, Zhang YY, Li LL, Xie F, Cai B, Cao L, Zheng GM, Dong L, Zhang ZW, Ding P,
Luo ZH, Ding CQ, Ma ZJ, Tang SH, Cao WX, Li CW, Hu HJ, Ma Y, Wu Y, Wang YX, Zhou KY, Liu SY, Chen YY, Li JT, Feng ZJ, Wang Y, Wang B, Li C, Song XL, Cai L, Zang CX, Zeng Y, Meng ZB, Fang HX, Ping XG (2016) Red List of China's Vertebrates. Biodiversity Science, 24, 500-551. (in Chinese and in English) [蒋志刚, 江建平, 王 跃招, 张鹗, 张雁云, 李立立, 谢锋, 蔡波, 曹亮, 郑光 美, 董路, 张正旺, 丁平, 罗振华, 丁长青, 马志军, 汤宋 华, 曹文宣, 李春旺, 胡慧建, 马勇, 吴毅, 王应祥, 周开 亚, 刘少英, 陈跃英, 李家堂, 冯祚建, 王燕, 王斌, 李 成, 宋雪琳, 蔡蕾, 藏春金鍂, 曾岩, 孟智斌, 方红霞, 平晓 鸽 (2016) 中国脊椎动物红色名录. 生物多样性, 24, 500-551.]

Jiang ZG, Liu SY, Wu Y, Jiang XL, Zhou KY (2017) China' mammalian diversity(2nd edition). Biodiversity Science, 25, 886-895. (in Chinese with English abstract) [蒋志刚, 刘少 英, 吴毅, 蒋学龙, 周开亚 (2017) 中国哺乳动物多样性 (第2版). 生物多样性, 25, 886-895.]

Leshowitz B (1969) Comparison of ROC curves from one- and two- interval rating-scale procedures. Journal of the Acoustical Society of America, 46, 399-402.

Li H, Aide TM, Ma Y, Liu W, Cao M (2007) Demand for rubber is causing the loss of high diversity rain forest in SW China. Biodiversity \& Conservation, 16, 1731-1745.

Li MY, Ju YW, Kumar S, Stohlgren TJ (2009) Modeling of potential habitat for endangered wild animals: A case study of gaur Bos gaurus. Journal of Northeast Forestry University, 37, 88-91. (in Chinese with English abstract) [李明阳, 巨云为, Kumar S, Stohlgren TJ (2009) 濒危野生动物潜在 生境空间建模方法——以印度野牛(Bos gaurus)为例. 东 北林业大学学报, 37, 88-91.]

Liao CH, Li P, Feng ZM, Zhang JH (2014) Area monitoring by remote sensing and spatiotemporal variation of rubber plantations in Xishuangbanna. Transactions of the Chinese Society of Agricultural Engineering, 30, 170-180. (in Chinese with English abstract) [廖谌婳, 李鹏, 封志明, 张景华 (2014) 西双版纳橡胶林面积遥感监测和时空变化. 农业 工程学报, 30, 170-180.]

Lian ZM, Yu GZ (2000) Edge effect and biodiversity. Chinese Biodiversity, 8, 120-125. (in Chinese with English abstract) [廉振民, 于广志 (2000) 边缘效应与生物多样性. 生物 多样性, 8, 120-125.]

Liu XN, Feng ZM, Jiang LG, Zhang JH (2012) Rubber plantations in Xishuangbanna: Remote sensing identification and digital mapping. Resources Science, 34, 1769-1780. (in Chinese with English abstract) [刘晓娜, 封志明, 姜鲁光, 张景华 (2012) 西双版纳橡胶林地的遥感识别与数字制 图. 资源科学, 34, 1769-1780.]

Margules CR, Pressey RL (2000) Systematic conservation planning. Nature, 405, 243-253.

Mishra C, Madhusudan MD, Datta A (2006) Mammals of the high altitudes of western "Arunachal Pradesh", eastern Himalaya: An assessment of threats and conservation needs. 
Oryx, 40, 1-7.

Myers N, Mittermeier RA, Mittermeier CG, Da FG, Kent J (2000) Biodiversity hotspots for conservation priorities. Nature, 403, 853-858.

Pan QH, Wang YX, Yan K (2007) A Field Guide to the Mammals of China. China Forestry Publishing House, Beijing. (in Chinese) [潘清华, 王应祥, 岩諧 (2007) 中国哺乳动 物彩色图鉴. 中国林业出版社, 北京.]

Pearson RG, Dawson TP (2003) Predicting the impacts of climate change on the distribution of species: Are bioclimate envelope models useful? Global Ecology \& Biogeography, 12, 361-371.

Phillips SJ, Anderson RP, Schapire RE (2006) Maximum entropy modeling of species geographic distributions. Ecological Modelling, 190, 231-259.

Shou ZH, Cai XT (1958) New record for gaur in Xishuangbanna, Yunnan. Science Bulletin, 3, 112-113. (in Chinese) [寿振黄, 蔡希陶 (1958) 云南西双版纳发现的野牛. 科 学通报, 3, 112-113.]

Smith AT, Xie Y (2009) A Guide to the Mammals of China. Hunan Education Press, Changsha. (in Chinese) [Smith AT, 解炎 (2009) 中国兽类野外手册. 湖南教育出版社, 长沙.]

Sreekar R, Huang G, Yasuda M, Quan RC, Goodale E, Richard T, Corlett RT, Tomlinson KW (2016) Effects of forests, roads and mistletoe on bird diversity in monoculture rubber plantations. Scientific Reports, 6, 21822.

Swets JA (1988) Measuring the accuracy of diagnostic systems. Science, 240, 1285-1293.

Wang YS, Xie BY, Wan FH, Xiao QM, Dai LY (2007) Application of ROC curve analysis in evaluating the performance of alien species' potential distribution models. Biodiversity Science, 15, 365-372. (in Chinese with English abstract) [王 运生, 谢丙炎, 万方浩, 肖启明, 戴良英 (2007) ROC曲 线分析在评价入侵物种分布模型中的应用. 生物多样性, 15, 365-372.]

Yang DH, Zhang JY (1988) Population and distribution of Bos gaurus in Yunnan. Chinese Journal of Zoology, 23(1), 39-41. (in Chinese) [杨德华, 张家银 (1988) 云南野牛的 数量分布. 动物学杂志, 23(1), 39-41.]
Yin F, Ma K, Liu DZ (2015) Population status, ecological habitat and threatened factors of wild gaur (Bos gaurus): A review. Journal of Beijing Normal University (Natural Science), 51, 504-510. (in Chinese with English abstract) [ $尹$ 峰, 马凯, 刘定震 (2015) 野牛的种群现状、生态习性及致 危因素. 北京师范大学学报(自然科学版), 51, 504-510.]

Yunnan Institute of Forest Inventory and Planning (1989) The Nature Reserve in Yunnan. China Forestry Publishing House, Beijing. (in Chinese) [云南省林业调查规划院 (1989) 云南自然保护区. 中国林业出版社, 北京.]

Zhang HL, Li ZX, Wang RC (2000) A study on Bos gaurus habitat using multivariate statistical techniques and GIS-Taking the Naban River Basin Biosphere Reserve in Xishuangbanna as an example. Tropical Geography, 20, 152-155. (in Chinese with English abstract) [张洪亮, 李芝 喜, 王人潮 (2000) 应用多元统计技术和GIS技术进行印 度野牛生境定量分析一一以西双版纳纳板河流域生物圈 保护区为例. 热带地理, 20, 152-155.]

Zhang HL, Wang RC (1999) GIS-based ecotope types and their relationship with survival of Bos gaurus. Chinese Journal of Applied Ecology, 10, 619-622. (in Chinese with English abstract) [张洪亮, 王人潮 (1999) 基于GIS的生境类型及其 与印度野牛生存关系的研究. 应用生态学报, 10 , 619-622.]

Zhang ZY, Yang HP, Luo AD (2016) Population, distribution and conservation status of gaur (Bos gaurus) in Xishuangbanna Prefecture. Forest Inventory and Planning, 41, 115-119. (in Chinese with English abstract) [张忠员, 杨鸿 培, 罗爱东 (2016) 西双版纳印度野牛种群数量、分布和 保护现状. 林业调查规划, 41, 115-119.]

Zhu ZH, Wu QA, Yang LP (2003) Present status and conservation strategy of wild animal and plant resources in Gaoligongshan National Nature Reserve. Forestry Science \& Technology, 28, 63-65. (in Chinese with English abstract) [朱振华, 冊其爱, 杨礼攀 (2003) 高黎贡山自然保护区 野生动植物资源现状及保护. 林业科技, 28, 63-65.]

(责任编辑：问文杰)

\section{附录 Supplementary Material}

\section{附录1 访问调查记录的印度野牛数量及分布}

Appendix 1 Population status of Bos gaurus by interview survey in Yunnan http://www.biodiversity-science.net/fileup/PDF/2018012-1.pdf

附录2 印度野牛分布区模拟的AUC曲线检验

Appendix 2 AUC curve test of gaur habitat stimulation http://www.biodiversity-science.net/fileup/PDF/2018012-2.pdf

\section{附录3 MaxEnt模型中研究物种对各种栖息地变量的响应曲线}

Appendix 3 Response curves of habitat variables in MaxEnt models http://www.biodiversity-science.net/fileup/PDF/2018012-3.pdf 
丁晨晨, 胡一鸣, 李春旺, 蒋志刚. 印度野牛在中国的分布及其栖息地适宜性分析. 生物多样性, 2018, 26 (9): 951-961. http://www.biodiversity-science.net/CN/10.17520/biods.2018012

附录1 访问调查记录的印度野牛数量及分布

Appendix 1 Population status of Bos gaurus by interview survey in Yunnan

\begin{tabular}{|c|c|c|c|c|c|c|c|}
\hline $\begin{array}{l}\text { 县名 } \\
\text { County }\end{array}$ & $\begin{array}{l}\text { 镇(乡) } \\
\text { Town }\end{array}$ & $\begin{array}{l}\text { 小地名 } \\
\text { Village }\end{array}$ & $\begin{array}{l}\text { 群数 } \\
\text { Groups }\end{array}$ & $\begin{array}{l}\text { 数量(头) } \\
\text { Population }\end{array}$ & $\begin{array}{l}\text { 发现时间 } \\
\text { Occurrence time }\end{array}$ & $\begin{array}{l}\text { 实体或痕迹 } \\
\text { Individual } \\
\text { or Trace }\end{array}$ & 被访人 \\
\hline \multirow[t]{5}{*}{ 㐨海 } & 槛宋 & 朝山寨(洋人房) & 1 & 11 & 2016 年 2 月 & 实体 & 普文才 \\
\hline & 秒满 & 糯有上寨 & 1 & $3-4$ & 2014 年 4 月 & 实体 & 马杨 \\
\hline & & 糯有下寨(金竹林) & 1 & $5-6$ & 2011 年 5 月 & 足迹 & 罗长富 \\
\hline & & 纳包村(金矿山) & 2 & 30 & 2016 年 3 月 & 实体 & 董永华 \\
\hline & & 老田寨后山 & 1 & $27-28$ & 2016 年 3 月 & 实体 & 李红亮 \\
\hline \multirow[t]{4}{*}{ 预腊 } & 预混 & 曼赛 & 0 & 0 & - & - & 张万青 \\
\hline & 象明 & 曼林 & 0 & 0 & - & - & 阿更 \\
\hline & & 新发 & 0 & 0 & - & - & 胡先生 \\
\hline & & 安乐 & 1 & $2-3$ & 1993 年 & 足迹 & 杨二 \\
\hline \multirow[t]{8}{*}{ 景洪 ～～～～～} & 嘎酒 & 墨江寨 & 0 & 0 & - & - & 曹麦郎 \\
\hline & 预养 & 曼卡 & 0 & 0 & - & - & 艾先生 \\
\hline & & 览养农场(七号山) & 1 & - & 1999 年 & 足迹 & 周先生 \\
\hline & 基诺 & 扎吕 & 1 & - & 2011 年 & 实体 & 林立周 \\
\hline & & 磨镯 & 1 & - & 1996 年 & 实体 & 李先生 \\
\hline & & 亚诺 & 1 & 10 & 2012 年 & 实体 & 飘先生 \\
\hline & 纳板河 & 过门山保护站 & 1 & $42-62$ & 2016 年 3 月 & 实体 & 曹先生 \\
\hline & 大渡岗 & 大渡岗 & 2 & $22-23$ & 1996 年 & 实体 & 李平 \\
\hline \multirow[t]{3}{*}{ 普洱 } & 思茅 & 茨竹林 & 2 & $23-24$ & 2016 年 3 月 & 实体(照片) & 曹加顺 \\
\hline & 发展河 & 林排坡(怕凉山) & 2 & 2 & 2016 年 1 月 & 实体(视频) & 龚林玉 \\
\hline & & 㐨乃(小金山) & 2 & $5-10$ & 2015 年 4 月 & 实体(照片) & 李学民 \\
\hline
\end{tabular}

空白表示具体数量及时间不清楚。The blank indicates that we did not get specific information. 
丁晨晨, 胡一鸣, 李春旺, 蒋志刚. 印度野牛在中国的分布及其栖息地适宜性分析. 生物多样性, 2018, 26 (9): 951-961. http://www.biodiversity-science.net/CN/10.17520/biods.2018012

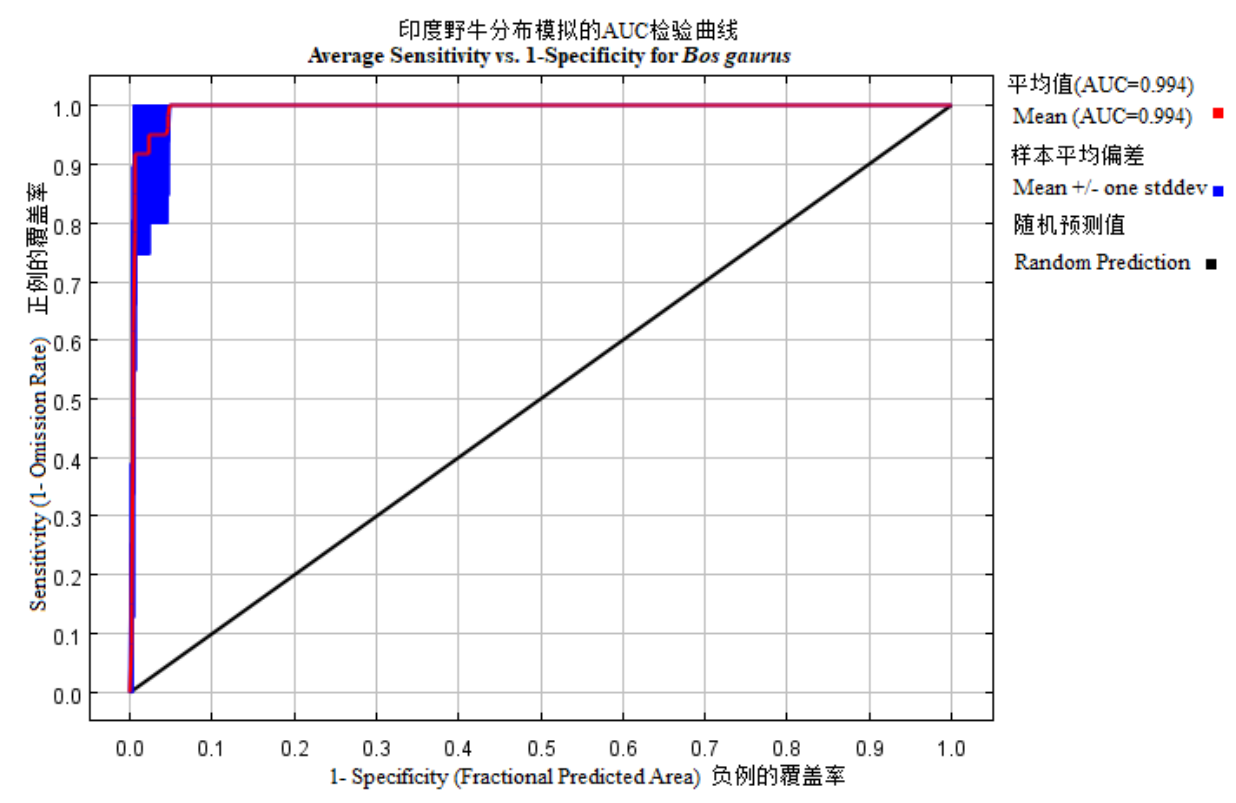

附录2 印度野牛分布区模拟的AUC曲线检验

Appendix 2 AUC curve test of gaur habitat stimulation 
丁晨晨, 胡一鸣, 李春旺, 蒋志刚. 印度野牛在中国的分布及其栖息地适宜性分析. 生物多样性, 2018, 26 (9): 951-961. http://www.biodiversity-science.net/CN/10.17520/biods.2018012

BI01

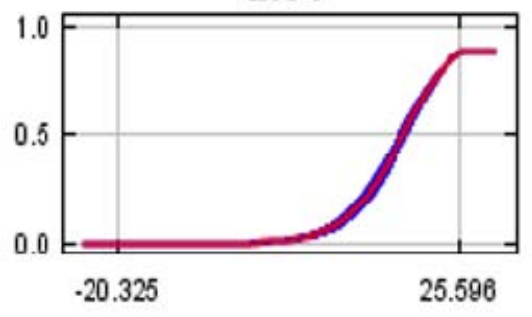

B107

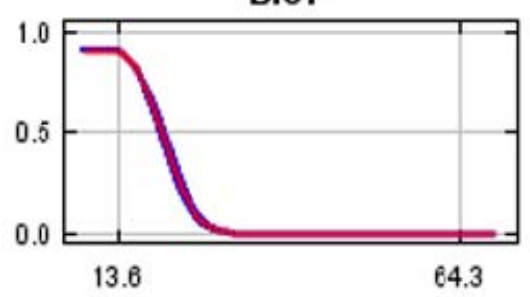

BI015

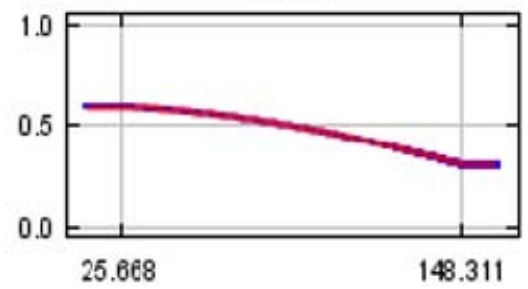

Alt.

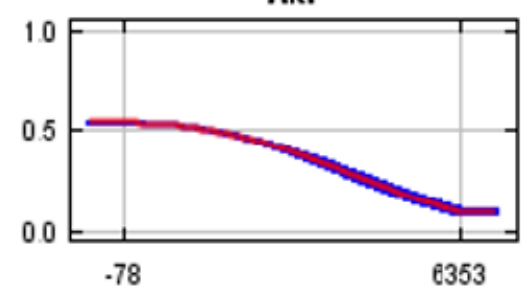

Dis_water

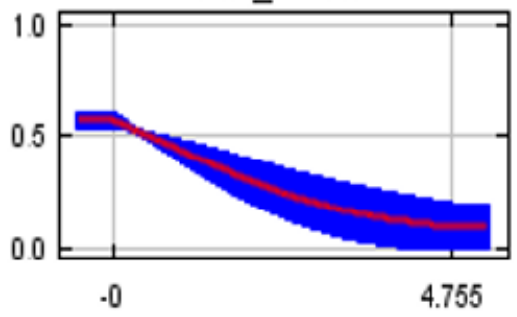

$\mathrm{BI03}$

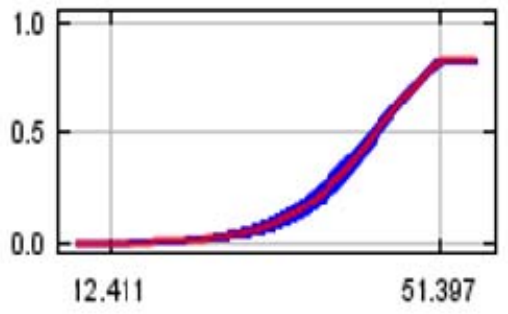

BI09

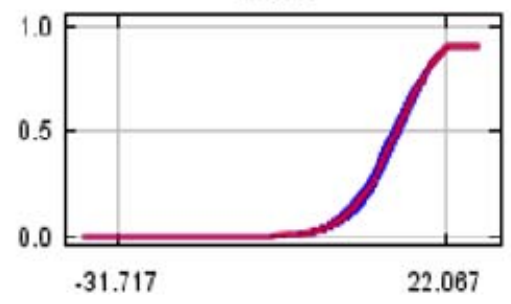

BI019

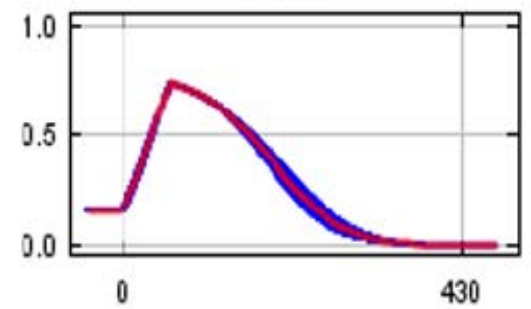

HFI

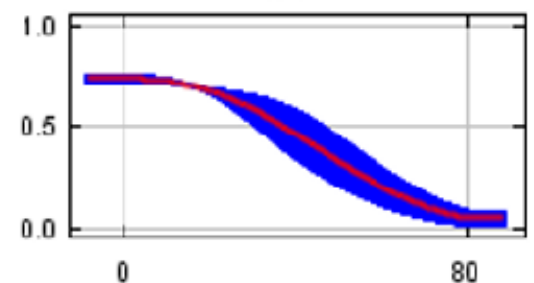

Dis_road

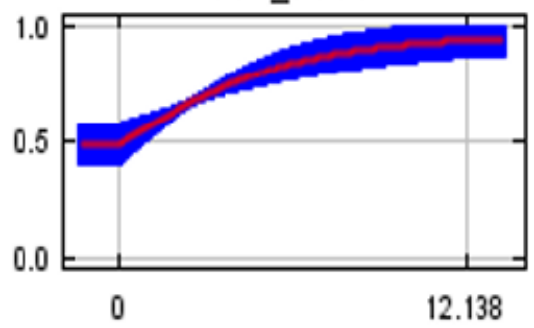

BI04

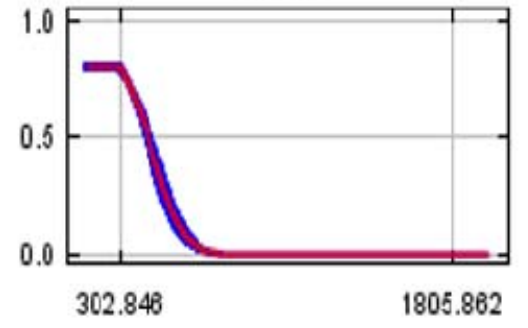

BI012

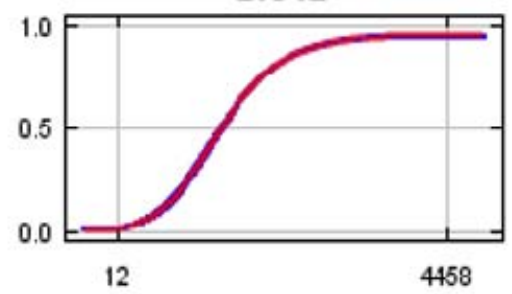

Slop.

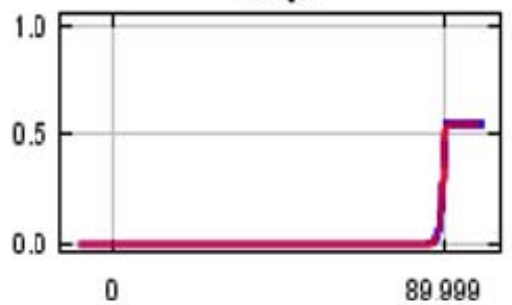

\section{LCI}

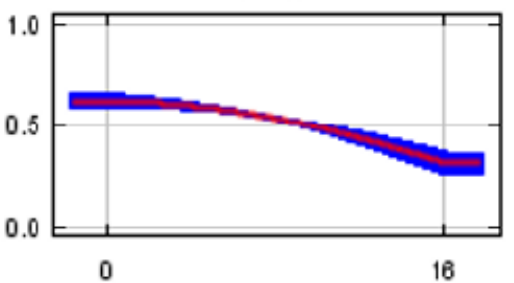

MaxEnt模型中研究物种对各种栖息地变量的响应曲线

Appendix 3 Response curves of habitat variables in MaxEnt models 